\title{
Assessment of Indoor Carcer Linked Radionuclides in Sokoto Urban Dwelling \\ ${ }^{1 *}$ Yusuf Ahijjo Musa \\ ${ }^{1}$ Musa Momoh \\ ${ }^{2}$ Adamu Nchama Baba-Kutigi
}

$1^{1 *}$ Department of Phyiscs, Usmanu Danfodiyo University, Sokoto-Nigeria

${ }^{2}$ Department of Phyiscs, Federal University, Dutsin-Ma, Katsina-Nigeria

${ }^{1 *}$ Usmanu Danfodiyo University, P.M.B. 2346, Sokoto-Nigeria

\section{Doi:10.5901/ajis.2013.v2n13p55}

\section{Abstract}

Radiation can be ambiguous to the layman. Typically, one only has an understanding of radiation from news, movies, or books. Largely these sources tend to sensationalize radiation, relating to solar and thermal radiations with little emphasis to ionizing radiations from primordial and anthropogenic radionuclides. Gamma-ray spectroscopy was used for determination of K-40 and Ra-226 in this study that was carried out by collecting air sample with Activated Charcoal Detectors (ACDs) mounted in thirty living apartment sample points in Sokoto. This provided information about the level of radionuclides present in the dwellings which have been implicated as a carcinogen to the lungs through ionizing radiations. Due to the sampling procedure in all the points, the results obtained now represent the entire dwelling. Thereby, allowing us to ascertain the environmental induced health impacts of K-40 and Ra-226.

Keywords: carcinogen, gamma-ray spectroscopy, ionization, radionuclides, Sokoto,

\section{Introduction}

Natural radioactivity is widely spread in the earth's environment and it exists in various geological formations like soils, rocks, plants, water and air (Malance et al., 1996, Abdo et al., 1999). As early as the days of the Manhattan Project, "health physicists in USA" have predicted that long term health effects from exposures to internally deposited alpha- and beta-emitting radioisotopes, inhaled or ingested from radioactive contaminated environment will be severe (Persson, 1994). Unstable nuclides are known as radioactive nuclides or radionuclides. They decay loosing excessive mass energy by the emission of particle and photons. There are two types of radionuclides. Thorium-232, Radium-226, Radon-222, and Lead-210 are Uranium progenies of health impacts. And Potassium-40 is a significant source because it has a half-life that is larger than the age of the earth (Ian, 2007). Mainly, they emit alpha particles, beta particle and gamma radiation, although they may decay by spontaneous fission. There are also artificial radionuclides, like ${ }^{60} \mathrm{Co}$ which is manufactured through the following reaction in equation (1) (Cember, 1983).

$$
{ }_{0}^{1} n+{ }_{27}^{59} \mathrm{Co} \rightarrow{ }_{27}^{60} \mathrm{C} \text { (Radioactive) }
$$

Advantages of gamma spectroscopy over alpha spectroscopy of ${ }^{210} \mathrm{~Pb}$ (Zaborska et al., 2007), are that gamma spectroscopy is non-destructive, several isotopes can be measured simultaneously in one spectrum (including ${ }^{210} \mathrm{~Pb}$ ), only physical preparation of the samples (no time consuming chemical separation) is needed and the detection efficiency is only dependent on physical parameters (Salbu et al., 2012). 


\section{The Study Area}

Sokoto metropolis is the study area. Sokoto lies on the Latitude $13.0833333^{\circ}$, Longitude $5.25^{\circ}$, and Altitude 895 (feet). The time zone in Sokoto is Africa/Lagos, sunrise at 06:27 and sunset at 18:46. It is located in the extreme northwest of Nigeria, bordering Niger and Benin Republics, near to the confluence of the Sokoto River and Rima River. It has an annual average temperature of $33.3^{\circ} \mathrm{C}$; on the whole, it is a very hot area. Sokoto state is in the dry Sahel, surrounded by sandy savannah and isolated hills (www.fallingrain.com/world/NI/51/sokoto.html,). Sokoto state is highly endowed with the wealth of limestone which attracted the chosen site of one existing cement company, and this limestone also contains a fairly amount of carcinogenic radionuclides (Adediran et al, 1998), and could emit the potential dose of this environmental health potencies that could possibly cause the lung cancer. This is no longer doubtful that low concentration of ${ }^{222} \mathrm{Rn}$ can as well deliver the radiation dose which can cause internal hazards to human (Field et al., 2000),

\section{Methodology}

This research was conducted on the use of a commercially purchased activated charcoal detectors (ACDs). ACDs are passive devices deployed for 1-7 days so as to measure the indoor radionuclides by adsorption on the active sites of the activated carbon (Oikawa et al., 2006). After sampling of the thirty gridded points randomly, so as to cover the entire Sokoto metropolis, the detector canisters are then sealed and sent to CERT, Zaria for analysis by sodium Iodide Nal $(T \ell)$ counter. After the equilibration period 21to24 days, the collectors can be directly gamma counted, or analytically prepared for liquid scintillation counting techniques. But in this case, the samples were gamma counted by sodium Iodide $\mathrm{Nal}(\mathrm{T} \ell)$ counter at the Centre for Energy Research and Training (CERT), Zaria. In the gamma counting method, the canisters containing $40 \mathrm{~g}$ of ACDs were used. A single measurement in one room is used to estimate the "whole house" concentration as this is an indoor aimed research. A total number of sixty absorber canisters were constructed using a plastic cylinder with measured diameter of $3.5 \mathrm{~cm}$ and height $5.0 \mathrm{~cm}$. Thirty (30) of which was equally perforated at the lid and a position for membrane filter, and well sealed round to avoid crossventilation that could probably reduce the expected radon concentration. And the remaining thirty (30) plastic cylinders with measured diameter $4.0 \mathrm{~cm}$ and height $6.0 \mathrm{~cm}$ without perforation to harbour other canisters with fairly smaller dimensions to enhance proper sealing until they are gamma counted were also prepared. The dose of every sampled point was also measured with the aid of Dose Rate Metre, Rados [RDS-120]. Dose rate is the interaction of gamma rays or a measure of the energy deposited in the tissue by gamma ray flux and is measured in Sievert (Sv) where 1Sv is 1joule per kilo. (Ahmad et al., 2000). Thus, the three principles of expressing radiometric measurements are; Activity concentration, Count per second and dose rate was extensively utilised as the result of the analysed result may show in this research.

\section{Materials}

A $400 \mathrm{~g}$ bottle of commercial ACDs produced by Reidel-De Haen AG Seelze Hannover of purity $93 \%$ and Batch № 18002, purchased from Hali Shua'ibu Science Laboratory Ltd. Sokoto, was used throughout the sampling exercise. An electronic chemical balance of Shimadzu Corporation, assembled by SPM Japan, which is capable of measuring between $0.1 \mathrm{mg}$ to $320 \mathrm{~g}$, was used to measure $40 \mathrm{~g}$ of ACDs needed in the canister. The balance was obtained from Central Laboratory, in the Faculty of Science, Usmanu Danfodiyo University, Sokoto.

\section{Result}

Samples were prepared following the procedures discussed in the previously. And the result was 
obtained subject to the following technique and analysis that shall be discussed herein.

\subsection{Sodium lodide ( $\mathrm{Nal}(\mathbf{T} \boldsymbol{\ell}))$ Detectors}

Gamma ray detection with a Nal $(T \ell)$ crystal was discovered by Robert Hofstadter in 1948. Later that year gamma spectroscopy with $\mathrm{Nal}(T \ell)$ was discovered by Hofstadter and his graduate student, John Mclntyre. The basic properties of the detector were researched and reported in the Physical Review over the next few years. Since then the scintillation detector (of which there are many different crystals), in particular the $\mathrm{Nal}(\mathrm{T} \ell)$ detector, have been used in a wonderful array of important physical experiments (William et al, 1989). Below is table 1: illustrating some features of $\mathrm{Nal}(T \ell)$ detector. It consists of a single crystal of thallium activated sodium iodide, optically coupled to the photocathode of a photomultiplier tube. When a gamma ray enters the detector, it interacts by causing ionization of the sodium iodide. This creates excited states in the crystal that decay by emitting visible light photons. This emission is called scintillation, which is the reason why this type of sensor is known as a scintillation detector. The thallium doping of the crystal is critical for shifting the wavelength of the light photons into the sensitive range of the photocathode.

Table 1: Show the Performance of a typical Nal $(T \ell)$ detector

\begin{tabular}{|l|c|}
\hline \multicolumn{1}{|c|}{ Material } & Nal $(T \ell)$ \\
\hline Density $\left(\mathrm{g} / \mathrm{cm}^{3}\right)$ & 3.67 \\
\hline Time Constant $(\mathrm{ns})$ & 230 \\
\hline Luminescence Wavelength $(\mathrm{nm})$ & 420 \\
\hline Relative Light Intensity & 100 \\
\hline Refractive Index & 1.85 \\
\hline
\end{tabular}

\subsection{Energy Calibration}

Energy Calibration involves identifying the locations of standard photo-peaks in the raw spectrum, then creating an adjusted (or calibrated) spectrum by interpolation from the raw positions to the standard (or ideal) positions. For a standard spectrum measured from 0.0 to $3.0 \mathrm{MeV}$ and digitised into 256 channels ( 0 to 255 ) each channel has a range of $11.72 \mathrm{keV}$. This defines the standard channel range for each IAEA defined energy window. For example, Potassium-40 in this research, having (1.37MeV - 1.57MeV) will be found in channels 116-133. In order for this to work, the channel positions of the photo-peaks in the raw spectra were entered as required. These low and high channel limits was obtained visually by using the View function of the raw spectra data. Below is the typical sketch of these resolutions obtained in figure 1.

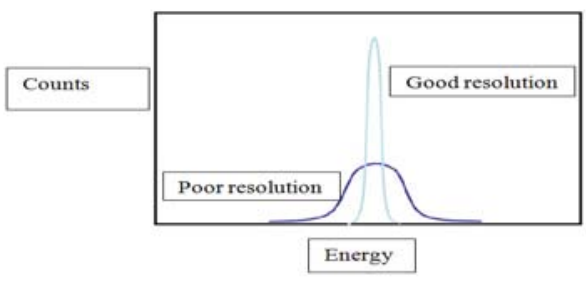

Figure 1: Energy Resolution

A high energy resolution means that the detector can discriminate between gamma-rays with similar energies. The more resolution a detector has, the more defined a gamma spectrum becomes. The resolution of a detector is defined as 
$\mathrm{R}=\frac{H_{0}}{F W H M}$

Where $\mathrm{H}_{0}$ is the centroid peak number and FWHM is the full-width half-maximum of the Peak.

\section{Discussion}

The analysed results of the thirty (30) samples within the grids of Sokoto urban dwelling from (CERT Zaria) is shown in the spectra of the figure 2:-5: below. The significance of this research focuses on unveiling the concentration of these radionuclides since there is strong epidemiological evidence that ionizing radiation from their alpha emission increases the risks of cancer (Preston et al., 2007); but the epidemiological data of the lung cancer will not be discussed here per se, rather, the potential concentration in $\mathrm{Bq} / \mathrm{kg}$ within each sample points and the concentration of $\mathrm{K}-40$ and Ra-226 will be fervently established.

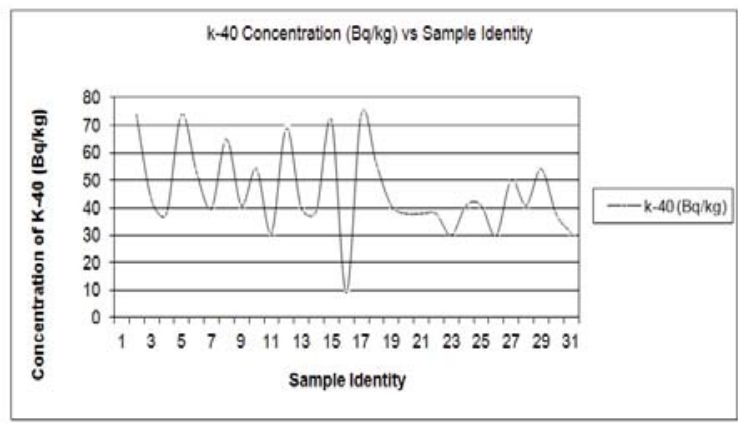

Figure 2: Indoor K-40 (Bq/kg) Spectra at various Sample point

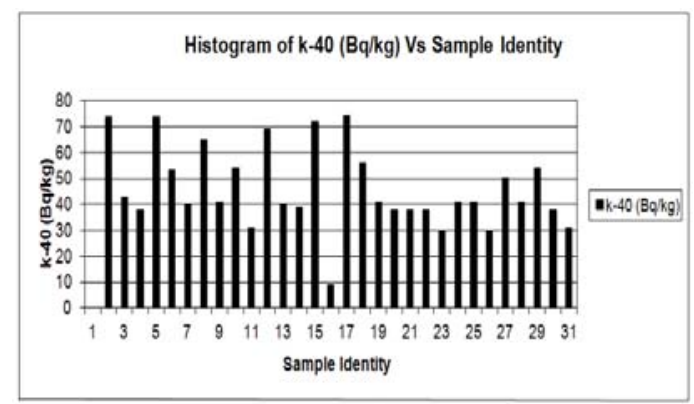

Figure 3: Indoor K-40 (Bq/kg) Spectra at various Sample Point

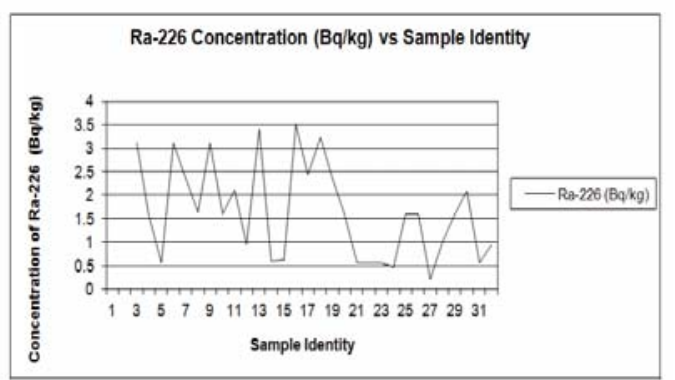

Figure 4: Indoor Ra-226 (Bq/kg) Spectra at various Sample Point 


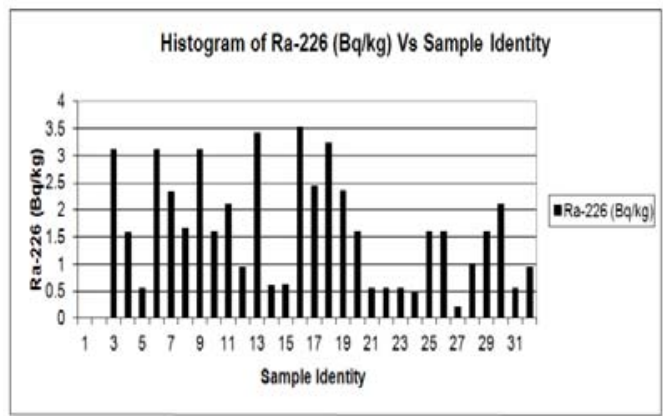

Figure 5: Histogram for Indoor Ra-226 (Bq/kg) Spectra at various Sample Point

\section{Conclusion}

Gamma ray spectrometry has been used to determine the radioactivity concentration of K-40 and Ra-226 in the indoor air of various sample collected within urban dwelling in Sokoto. Since this research has laid a mile stone to exposing the dangers of indoor ionizing radiation in the urban dwelling of Sokoto, then it is only prudent that anthropogenic remedial measures are employed to halt further health hazards due it. Only very few patients recover from cancer of any form let alone lung cancer which its chances of survival is very narrow. While it is not practically possible to fix these radiation anomalies with our hands, but it is quite simple to increase our ventilations at home and avoid too frequent exposure to second hand smoke. The method used to assess this indoor concentration could also be used to estimate other forms of radionuclides concentration for radiation protection purposes. Health wise, work is currently on for determination of other radionuclides known to cause internal health hazards to human within Sokoto city to allow us have comprehensive information on this result.

\section{Acknowledgement}

This research was successfully achieved due to the herculean task, diversified support and painstaking effort of the following persons: Mallam Adam S. Sa'idu an Academic Technologist, Centre for Energy Research and Training, Zaria Mallam A.A Musa Chief Academic Technologist, (Chief Co-ordinator Physics Laboratories), Usmanu Danfodiyo University Sokoto

Mallam Awalu Ibrahim a Principal Academic Technologist, (Head of Electronics unit of Physics Laboratory, Usmanu Danfodiyo University Sokoto

\section{References}

Abdo Aly, Hassan A.A., Huwait M.H.\& M.R.A., Fourth Rad Phys Conf, Alexandria, Egypt, 15-19 November, 1999, 632

Adediran JA, Oguntoyinbo FI, Omonode R and RA Sobulo, 1998. Agronomic evaluation of phosphorus fertilizers, Pp-21-22.

Ahmad, A.A., El-Hussein, A., Mohamemed, A., Abd El-Hady, M., Ali, A.E., Barakat, A., 2001. Diurnal and seasonal variation of short-lived radon progeny concentration and atmospheric temporal variations of 210Pb and 7Be in Egypt. Journal of Atmospheric Environment, 35, 4305-4313.

Cember H. (1983) Introduction to Health Physics $2^{\text {nd }}$ ed. Mc Graw-Hilllnc. New York. Pp520.

Field RW, Steck DJ, Smith BJ, Brus CP, Fisher EL, Neuberger JS, Platz CE, Robinson RA, Woolson RF, Lynch CF: Residential Radon Gas Exposure and Lung Cancer: The Iowa Radon Lung Cancer Study, American J ournal of Epidemiology 151(11):1091-102,2000.

Ian Rittersdorf, (2007), Gamma Ray Spectroscopy, Nuclear Engineering \& Radiological Sciences. March 
20, 2007, Pp-20

Malance A., Gaidolfi I., Pessina V \& Dallara G., J Environ Radioact, (1996), Pp. 55

Oikawa S, Kanno N, Sanada T, Abukawa J, Higuchi H J Environ Radioact. 2006; 87(3):239-45.

Persson L. (1994)The Auger electron effect in radiation dosimetry. Health Phys, 67:471-476.

Preston DL, Ron E, Tokuoka S, Funamoto S, Nishi N, Soda M, Mabuchi K, Kodama K. (2007). Solid cancer incidence in atomic bomb survivors: 1958-1998. Radiat Res 168:1- 64;

Salbu, B., Burkitbaev, M., Strømman, G., Shishkov, I., Kayukov, P., Uralbekov, B. \& Rosseland, B. 0. (2012). Environmental impact assessment of radionuclides and trace elements at the Kurday $U$ mining site, Kazakhstan. Journal of Environmental Radioactivity. In press.

The Geography of Sokoto state at a glance www.fallingrain.com/world/NI/51/sokoto.html, retrieved on $6^{\text {th }}$ September, 2013.

William R.; Field, Steck, Daniel J.; Lynch, Charles F. (1999). "Exposure to Atmospheric Radon". Environmental Health Perspectives 107(2): 123.doi: 10.2307/3434368.

Zaborska, A., Carroll, J., Papucci, C., Pempkowiak, J., Intercomparison of alpha and gamma spectrometry techniques used in 210Pb geochronology. J. Env. Rad. 93 (2007) 38 - 50. 